\title{
Apropiaciones de los lugares del miedo y la memoria: percepciones de las mujeres de la Comuna 1, Medellín, Colombia
}

\section{APPROPRIATIONS OF PLACES OF FEAR AND MEMORY: PERCEPTIONS OF WOMEN FROM COMUNA 1, MEDELLÍN, COLOMBIA}

APROPRIAÇÕES DE LUGARES DE MEDO E MEMÓRIA: PERCEPÇÕES DE MULHERES DA COMUNA 1, MEDELLÍN, COLÔMBIA
Pineda Zapata, M. I. (2018). Apropiaciones de los lugares del miedo y la memoria: percepciones de las mujeres de la Comuna 1, Medellín, Colombia. Perspectiva Geográfica, 23(2). 10.19053/01233769.7256

\section{Recepción:}

13 de septiembre de 2017

Evaluación:

15 de mayo de 2018

Aprobación:

30 de julio de 2018

\section{Resumen}

En este artículo se describen las percepciones y apropiaciones que hacen las mujeres de los lugares del miedo y la memoria en los barrios La Avanzada y Carpinelo ubicados en la Comuna 1 de la ciudad de Medellín, Colombia. En ese sentido, el artículo responde a las preguntas: ¿cuáles son los lugares del miedo y la memoria para las mujeres? ¿Qué percepciones tienen y cómo se apropian de estos? Conceptualmente, la argumentación teje la relación entre género y lugar desde el enfoque cultural y la geografía feminista; en lo metodológico, el trabajo de campo incluyó recorridos por los lugares, elaboración de cartografías sociales y entrevistas grupales e individuales. Los resultados aquí planteados muestran cómo la percepción de miedo e inseguridad que sienten las mujeres en algunos lugares limitan su uso y su apropiación desde la autonomía y la libertad, elementos necesarios para planear ciudades seguras para las mujeres.

Palabras claves: ciudad, lugar, memoria, mujer, territorio.

1 Socióloga de la Universidad de Antioquia, politóloga de la Universidad Nacional de Colombia, magíster en Planeación Urbano Regional, Universidad Nacional de Colombia. Docente en la Secretaría de Educación de Medellín. Correo electrónico: maisapineda@yahoo.com.ar. 


\section{Abstract}

The present article describes how women of La Avanzada and Carpinelo, neighborhoods of Medellin, have appropriated places within them, that evoke fear and memory. The article answers the questions: ¿What are the places of fear and memory for women, what perceptions do they have and how do they appropriate them? The argumentation weaves the relationship between gender and territory from two approaches: culture and feminist geography. The methodological included tours of the places, elaboration of social cartographies and group and individual interviews. The results show how fear and insecurity that women feel in some places of their neighborhoods, have been creating boundaries that prevent its uses. These factors have limited the appropriation of those places by the community, restricting liberty and autonomy, crucial factors to the foundation of a city perceived safe for women.

Keywords: city, places, memory, territory, women.

\section{Resumo}

Neste artigo se descreve a apropriação social que as mulheres, das comunidades La Avanzada e Carpinelo (Comuna 1, Medellín Colombia), fazem de locais que são ou foram aterradores. Nesse sentido, o artigo responde às questões: quais são os lugares de medo e memória para as mulheres, quais são suas percepções e como elas se apropriam delas? Teoricamente é discutida a relação de gênero e território, com um enfoque cultural do território e as geografias feministas. Os resultados expostos neste trabalho demonstram como a percepção de medo e insegurança, que aquelas mulheres sentem em certos locais, impede e limita o uso, desfrute e apropriação destes, vistos desde a autonomia e a liberdade, elementos indispensáveis para conceber cidades que sejam seguras para as mulheres.

Palavras-chave: cidades, memoria, mulheres, locais, território. 


\section{A manera de introducción}

"Me siento vulnerable cuando camino por ciertos lugares de mi barrio, cuando voy al centro también hay de esos lugares, sobre todo de noche, por esos [lugares] no camino"

(Mujer del barrio Carpinelo, 2014)

Comenzar la reflexión con este testimonio devela una postura no solo personal, y, en tanto personal, política, sino también una apuesta académica que busca evidenciar la importancia de dotar de sentido las reflexiones técnicas y académicas sobre la apropiación territorial con las voces de las mujeres y sus percepciones sobre aquellos lugares que no representan seguridad ni libertad para ellas. Aunque se podrían tejer diferentes caminos para comprender e interpretar la narrativa de esta mujer, la presente reflexión privilegia el estudio de los lugares desde una perspectiva de género fundamentada en los estudios culturales y la geografía feminista.

Desde este marco de comprensión, el territorio es trama y tejido de lugares y es el resultado de una construcción social, es decir, permea y está permeando relaciones, dispositivos, estereotipos e imaginarios de género ligados a una concepción de mundo y una construcción individual de sujeto. En ese sentido, el territorio opera como una trama de lugares diferenciados y como dispositivo identitario que permite a hombres y mujeres construir relaciones sociales, culturales y territoriales.

Lagarde (1996) comprende el género como una construcción cultural, es decir que cada grupo social tiene una concepción singular del género, dependiendo de su visión del mundo y de sus tradiciones. El género es una construcción simbólica $\mathrm{y}$, como tal, es un conjunto de representaciones sociocul- turales asignadas a las personas a partir del sexo que definen el estatus, la identidad, la percepción frente a la vida, los roles y las prácticas. La relación planteada implica comprender, de un lado, que los individuos, hombres y mujeres, se construyen socialmente a partir de categorías de género y, de otro, que el territorio y los lugares no son neutrales en tanto producción social.

Es importante plantear que, en el contexto local, aunque se reconoce el avance en el desarrollo de estrategias con enfoque de género, producto de la movilización sociopolítica y de la incidencia de mandatos internacionales que instan a los Estados a definir programas y proyectos para disminuir la exclusión de las mujeres, aún perviven imaginarios sociales y culturales, prácticas y discursos que suponen desventajas e inequidades para ellas. Lo anterior se expresa, entre otros, en brechas en el acceso a oportunidades, imaginarios sobre la inferioridad de las mujeres para ejercer algunas actividades, asociación de la feminidad con debilidad emocional, ideal de la maternidad como única vía para la realización de las mujeres, falta de reconocimiento del trabajo reproductivo, idea de que el mundo de lo doméstico es exclusivamente femenino y aumento de los homicidios basados en la condición de género (feminicidios).

En el caso particular de la Comuna 1 de la ciudad de Medellín, la Encuesta de Calidad de Vida del 2012 (Departamento Administrativo de Planeación, 2012) presenta datos que corroboran lo anterior: el $27 \%$ de la población encuestada en la comuna percibe que en los últimos años no se ha logrado mayor igualdad de oportunidades entre hombres y mujeres, el $74 \%$ percibe la sociedad como machista y el $73 \%$ afirma que en la ciudad aún se discrimina a la mujer. Una de las lideresas de la comuna, asociada al Observatorio 
de Seguridad Humana, afirma que "el territorio no brinda garantías para las mujeres ni para sus cuerpos que defienden como primer territorio de dignidad, y que es usado y abusado. En ese sentido, asume que el futuro del territorio es desesperanzador, en tanto el poder masculino continúa imponiéndose a través de la violencia intrafamiliar y por parte de los actores ilegales que asumen la autoridad bajo amenazas" (Mujer, barrio La Avanzada, 2014).

Por su parte, la Personería de Medellín (2013) reportó para el 2012 (de acuerdo a las denuncias atendidas) que la Comuna 1 fue un punto neurálgico de peligrosidad para las mujeres, representado en los altos índices de violencia intrafamiliar, feminicidios y restricción de los horarios para su movilidad. Ese tipo de situaciones dificulta el desarrollo pleno, la movilidad y la autonomía de las mujeres para apropiarse de los diferentes lugares del territorio, sea por temor o por limitaciones reales, por ejemplo en espacios que son utilizados para el microtráfico.

La Secretaría de las Mujeres de la Alcaldía de Medellín (2011) reconoce además que la pervivencia de patrones históricos de socialización y de configuración de la feminidad pueden favorecer o, por el contrario, desestimular el uso de ciertos espacios. Las niñas, por ejemplo, tienen patrones de movilidad más restringidos que los niños: por lo general ellas pueden moverse hasta donde alcance la mano-ojo de la madre o cuidadora, tienen menos permisos para alejarse de la casa o del barrio, transitar en bicicleta o patines, se les prohíben ciertos lugares dado que la calle es percibida como peligrosa en sí misma, condicionando así su asistencia a ciertos lugares y limitando la apropiación y la movilidad.

Sobre este tema y el uso que hacen las mujeres de los lugares y espacios públicos, Buckingham (2010) advierte que:
En la esfera urbana, el uso irrestricto del espacio público puede ser a la vez un lujo y una fuente de temor y miedo a la violencia. Dentro del derecho a la ciudad, satisfacer un derecho neutral al uso de espacios públicos no toma en cuenta las relaciones patriarcales de poder y control que se producen en esos mismos espacios. Para las mujeres, existe un riesgo mucho mayor de violencia sexual que para los hombres y, como resultado de ello, tienden a evitar ciertas zonas que consideran peligrosas (p. 8).

Reconocemos la importancia de generar reflexiones sobre las apropiaciones que hacen las mujeres del territorio, por lo cual este artículo nombra los lugares del miedo y la memoria para las mujeres habitantes de La Avanzada y Carpinelo, dos barrios de la Comuna 1 de la ciudad de Medellín, y narra las percepciones que tienen de estos. Los resultados aquí presentados hacen parte del trabajo de campo realizado durante el año 2014 en estos dos barrios, el cual incluyó la realización de cartografías sociales con mujeres adolescentes, adultas y adultas mayores, entrevistas y recorridos por el territorio; algunos de sus relatos son citados para dar fuerza a los elementos cualitativos encontrados. Las mujeres que participaron en la investigación son actoras estratégicas del territorio desde los diferentes roles que ejercen en su comunidad: amas de casa, estudiantes, lideresas y fundadoras de los dos barrios.

Finalmente, es importante anotar que, desde hace aproximadamente diez años, la Comuna 1 ha sido objeto de una importante intervención urbana a partir de la implementación del Proyecto Urbano Integral (PUI), instrumento que abarca las dimensiones físicas, sociales e institucionales; en este contexto cobra pertinencia la pregunta sobre las apropiaciones que realizan las mujeres de los lugares que evocan miedo y memoria. Los dos barrios se focalizaron teniendo en cuenta que allí hay organizaciones de 
mujeres fortalecidas que han avanzando en el ejercicio de pensar, preguntar e intervenir la planeación del territorio.

\section{Precisiones conceptuales}

El territorio es una construcción social, una trama de lugares y una expresión de la espacialización del poder; esta aproximación implica asumir, entre otras cosas, que en este se materializan relaciones de género como producto de la construcción social e histórica y como forma primaria de las relaciones significantes de poder. Comprender el territorio desde la perspectiva de género implica asumir que los usos, las apropiaciones y los recorridos que hacen hombres y mujeres de los diferentes lugares están mediados por roles sociales y culturales que se asocian a unas estructuras particulares de poder; en ese sentido, se puede evidenciar que las mujeres hacen un uso diferencial de los lugares públicos y privados:

De la división sexual del trabajo, enmarcadas en el seno de la familia, los hombres se encargan de las tareas productivas, las relacionadas con el mercado, que se dan en el ámbito de lo público, mientras que las mujeres son las encargadas de las tareas reproductivas, que se dan en el ámbito de lo doméstico (Durán, 1998, p. 54).

Para McDowell (1999), las relaciones de poder que definen los lugares instauran normas que marcan límites espaciales y sociales: determinan quién pertenece a un lugar, quién queda excluido y cómo se emplaza determinada experiencia:

Más allá del cuerpo, se multiplican los emplazamientos materiales y simbólicos del poder: los puestos de trabajo, los espacios domésticos, los lugares de esparcimiento, los centros comerciales, las plazas, el barrio, la comunidad; todos ellos pueden ser analizados como variaciones geográficas de la masculinidad, la feminidad y sus significados (p. 89).

Por su parte, Massolo (2005) muestra cómo el modelo de zonificación se basa en roles estereotipados según el género, a partir de lo cual el hombre, como responsable de proporcionar el sustento, tiene un horario laboral convencional, mientras que la mujer, en su rol de ama de casa, utiliza el entorno urbano de forma diferente: llevar a los hijos e hijas al colegio, hacer las compras y destinar la mayor parte del tiempo a la atención del hogar y de otros miembros de la familia.

Vergara (2013) plantea que el territorio es una trama y un tejido de lugares, y, en ese sentido, su producción está determinada por la singularización del espacio, que es el resultado de las emociones y los significantes que los actores establecen en los lugares a partir de prácticas, demarcaciones y delimitaciones que les imprimen una vocación y un carácter particular.

Es el espacio circunscrito y demarcado que contiene y determina singularidad emosignificante y expresiva; es el espacio donde las prácticas humanas construyen el lazo social, (re)elaboran la memoria a través de la imaginación demarcándolos por el afecto y la significación (Vergara, 2013, p. 35).

En esta definición se destaca la relevancia del significado y la emotividad del lugar asociada a la producción de placer o padecimiento. Los lugares no son espacios aislados, sino interconectados, y adquieren sentido cuando se instalan en la memoria de hombres y mujeres, como sujetos sociales, a partir de prácticas, vivencias y percepciones, entre otros; 
en ese sentido, la esquina donde se vende comida, la casa que es a su vez almacén, tienda o miscelánea y la cancha de fútbol usada por hombres jóvenes son lugares en donde se dan actividades recurrentes y se identifican usos, significados y afectividades particulares.

Para Escobar (2005), el lugar como experiencia de una localidad específica, con algún grado de enraizamiento, linderos y conexión con la vida diaria, genera lazos de pertenencia y de identidad cambiantes. El lugar constituye un conjunto de significados que son dados a partir de los usos locales, a pesar de la existencia de contextos de poder trasnacionales. Esta argumentación parte de reconocer que el lugar, como concepto y posibilidad metodológica para la comprensión, es marginal en el debate de lo global y lo local:

La desaparición del lugar es un reflejo de la asimetría existente entre lo global y lo local en la mayor parte de la literatura contemporánea sobre la globalización, en la que lo global está asociado al espacio, el capital, la historia y la acción humana mientras lo local, por el contrario, es vinculado al lugar, el trabajo y las tradiciones, así como sucede con las mujeres, las minorías, los pobres y uno podría añadir, las culturas locales (Escobar, 2005, pp. 127-128).

Desde una suerte de defensa del lugar, Escobar retoma a Lefebvre y su noción de lugar como una forma de espacio vivido y enraizado, y cuya reapropiación debería ser parte de las agendas políticas. Así mismo argumenta que, pese a la globalización y a la creciente deslocalización de la vida social, el lugar es una fuente importante de cultura e identidad. Por otra parte y, coherente con la intencionalidad metodológica definida, se delimitaron dos lugares: los del miedo y la memoria como espacios que permiten hallar significaciones subjetivas y colectivas desde la subordinación y la resistencia de las mujeres habitantes de dos barrios de la Comuna 1 de la ciudad de Medellín.

En ese sentido, se puede afirmar que los lugares del miedo son aquellos que generan sentimientos y afectos particulares de choque y sorpresa por la percepción de peligros inminentes, en este caso, para las mujeres. En esos lugares han sucedido acontecimientos, pasados y presentes, importantes y significativos para la vida de las mujeres, han acontecido prácticas, abusos y ritualizaciones que marcan el imaginario y restringen su apropiación, por ejemplo, lugares donde se han encontrado cuerpos sin vida de mujeres, lugares oscuros o donde han ocurrido abusos sexuales.

Niño Murcia (2002) relaciona el miedo y la memoria como un tipo de interacción y acto comunicativo que es producido, recibido y situado en un contexto sociocultural. Por su parte, Sánchez, Jaramillo y Villa (2004) afirman que el miedo es una construcción social, en tanto se experimenta individualmente, se construye socialmente y se interpreta desde contextos culturales específicos, es decir que, más allá de una respuesta biológica, el miedo es una percepción social sobre lo que es amenazante y sobre las maneras de responder, desde anclajes sociales y culturales específicos, a esa amenaza (p. 17).

En cuanto a los lugares de la memoria, son comprendidos como aquellos que evocan imágenes y representaciones sentidas. La memoria se comprende como el lazo que simboliza y evoca prácticas, imaginarios, valores e ideas pasadas, pero que le dan significado al presente. Los lugares de la memoria marcan o dejan huella en la vida individual y colectiva porque están cargados de sentido, dada la importancia de los hechos que ocurrieron allí. 
En los lugares de la memoria devienen percepciones presentes y pasadas, esas últimas no como trayectorias, sino como experiencias sedimentadas y conocimientos incorporados que dotan de sentido el presente. Para Javeau (2000) los lugares de la memoria "desempeñan en el recuerdo, el papel de lugares que deben ser señalados como notorios, donde se concentran, con una intensidad a veces extrema, las emociones" (p. 172).

\section{Lectura del territorio: Comuna 1, Medellín, Colombia ${ }^{2}$}

La Comuna 1 se encuentra localizada en la zona nororiental de la ciudad de Medellín, Colombia; limita por el norte con el municipio de Bello, por el oriente con el corregimiento de Santa Elena, por el sur con la Comuna 3 Manrique y por el occidente con la Comuna 2 Santa Cruz. La Comuna 1 cuenta con un área de 310 hectáreas y está conformada por 12 barrios reconocidos por el Departamento Administrativo de Planeación Municipal: Santo Domingo 1, Santo Domingo 2, Granizal, Popular, Moscú 2, Villa Guadalupe, San Pablo, Carpinelo, El Compromiso, Aldea Pablo VI, La Esperanza 2 y La Avanzada.

No obstante, según información del Plan de Desarrollo de la Comuna (Corporación Convivamos, 2009), los habitantes nombran otros barrios como parte de su territorio, aunque no cuenten con reconocimiento por parte de la Administración Municipal: Nuevo Horizonte, Santa María La Torre, Popular 1, Popular 2 parte central, Popular 2 parte alta, Santa Cecilia 1,

2 Los datos presentados corresponden a los reportados por fuentes oficiales entre los años 2011 y 2015. Algunos, aunque parecen estar desactualizados, son los últimos ofrecidos por dichas fuentes.

Vol. $23 \mathrm{~N}^{\circ} 2$

julio - diciembre de 2018

pp. 83-100
Santa Cecilia 2, Marco Fidel Suárez, Villa Guadalupe parte central, Villa Guadalupe parte baja, San Pablo 1, San Pablo 2, Carpinelo 2 y Nuestra Señora del Rocío. Los barrios denominados “de riesgo" en esta comuna son: Carpinelo, El Compromiso, Aldea Pablo VI, La Avanzada y La Esperanza 2.

Según información de la Encuesta de Calidad de Vida (ECV) (Departamento Administrativo de Planeación, 2012), para del 2012 la Comuna 1 contaba con una población total de 128.447 habitantes, de los cuales el $47 \%$ son hombres y el $53 \%$ mujeres. De acuerdo con los datos presentados por esta misma fuente, el estrato socioeconómico predominante en la Comuna 1 corresponde al bajo, con el 59,6\% de las viviendas, y el bajo-bajo, con el 40,4\%. Para el 2012, la Comuna 1 contaba con un índice de calidad de vida de 76,88 , seis puntos por debajo del índice total para la ciudad, que fue de 83,38; el índice multidimensional de calidad de vida (IMCV) para la comuna fue de 32,88 y para el resto de la ciudad fue de 47,63. Estas cifras ubican a la Comuna 1 como parte integrante de las comunas urbanas con menores índices de calidad de vida, al lado de Santa Cruz, Villa Hermosa y Manrique.

En el tema de violencia urbana ${ }^{3}$, la Personería de Medellín (2013) emitió una alerta en el 2012 para las comunas 1 y 2 en donde, de manera contraria al comportamiento del resto de comunas y corregimientos de la ciudad, la tasa de homicidios para ese año aumentó con respecto al anterior. En cuanto

3 Desde mediados de la década de los ochenta, la ciudad de Medellín fue el escenario donde se conformaron grupos armados ilegales con fuertes identidades y adscripciones territoriales por cuadras y barrios denominados "bandas" y "combos". Según la investigación del Observatorio de Seguridad Humana de Medellín (2012), estos combos y bandas utilizaron la oferta del servicio ilegal de protección violenta del territorio como una de las formas para legitimarse y realizar el cobro de una tributación extorsiva a los habitantes y los comerciantes. 
a los indicadores asociados al imaginario de hombres y mujeres sobre las percepciones de género, la ECV (2012) presentó los siguientes datos para un total de 36.995 hogares en la Comuna 1: “en el $12,74 \%$ de los hogares consideran que los hombres son mejores líderes políticos que las mujeres. En el $15,05 \%$ de los hogares consideran que obtener un título universitario es más importante para un hombre que para una mujer".

Estos datos muestran que las prácticas, las visiones y las percepciones que se refuerzan alrededor de los roles de género en los diferentes espacios de socialización aún continúan siendo desfavorables para las mujeres, en tanto aún pervive en las familias el imaginario según el cual los hombres son mejores líderes, lo cual desfavorece, a su vez, el acceso de las mujeres al escenario público. Las diferencias de género y los imaginarios que se refuerzan y se comparten por hombres y mujeres ordenan, legitiman y disciplinan prácticas y discursos políticos y generan condiciones de inequidad para las mujeres.

Podría afirmarse que los discursos y las visiones sobre el género de las mujeres y los hombres de la Comuna 1 refuerzan la escisión tradicional entre el mundo de lo privado y lo público; en ese sentido, el mundo del hogar, el cuidado de los otros, la crianza de los niños y las niñas y todo lo relacionado al mundo reproductivo es una esfera privilegiada para las mujeres. Por su parte, la Secretaría de las Mujeres de la Alcaldía de Medellín (2011) presentó las principales problemáticas que han conducido a la desigualdad e inequidad de las mujeres en esta comuna. La información se presenta en la Tabla 1.

\section{TABLA 1: PRINCIPALES PROBLEMÁTICAS DE LAS MUJERES, COMUNA 1, MEDELLÍN}

\section{Problemáticas políticas}

Baja incidencia de las mujeres en los espacios políticos institucionales de toma de decisiones.

\section{Problemáticas territoriales}

Insuficientes espacios y escenarios para la recreación de las niñas, adolescentes y mujeres.

Predios no legalizados.

Alto porcentaje de personas sin acceso a servicios básicos.

\section{Problemáticas económico-sociales}

Bajos niveles de autoestima y autocuidado de las mujeres.

Los empleos no implican salarios ni actividades dignas.

Incremento de la prostitución.

Pobreza extrema.

Incremento permanente de población en situación de desplazamiento, en su mayoría, mujeres, niños y niñas.

Bajo nivel de ingresos de las mujeres.

Violencia de género. 


\section{Percepciones y apropiaciones} de las mujeres sobre los lugares del miedo y la memoria: barrios La Avanzada y Carpinelo

\subsection{Lugares del miedo}

Las mujeres del barrio La Avanzada identificaron como lugares del miedo a La Curva y El Plan, que son descritos como lugares oscuros, solitarios y peligrosos por los cuales evitan transitar, que generan sentimientos de temor, miedo y padecimiento. Aunque no fue posible rastrear datos exactos de casos presentados en estos lugares, las mujeres que participaron de la investigación, desde sus narrativas, afirmaron que allí han ocurrido casos de violencia de género (violaciones, abusos sexuales y homicidios), lo cual impide su apropiación. Estos dos lugares tienen escaso alumbrado público, son solitarios y están rodeados de árboles, condiciones que no generan seguridad para las mujeres.

Las dinámicas sociales en los lugares del miedo en el barrio La Avanzada son diferenciadas dependiendo de la hora y el día de la semana, dada su cercanía a una institución educativa. El Plan, aunque cuenta con juegos infantiles, es un lugar descrito como solitario después de los horarios de entrada y salida de la institución; a medio día, es usado por niños y niñas que después de estudiar utilizan los juegos infantiles. Esa dinámica social en El Plan cambia en la noche, cuando es apropiado por hombres jóvenes que consumen sustancias psicoactivas y "vigilan" el territorio, en tanto lugar estratégico para observar hacia el asentamiento o invasión conocida como El Pinar, perteneciente al municipio de Bello, y hacia la vía principal para observar el barrio Santo Domingo Savio, que es también una de las centralidades de la Comuna 1.
Por su parte, el lugar conocido como La Curva se encuentra delimitado por un camino que se deriva de la vía principal. Es un camino de paso y su apropiación es esporádica porque se da principalmente en los horarios de entrada y salida de la institución educativa que se encuentra cerca.

Carlos se fue una vez a coger una madera por allá arriba por donde las monjas, se fue a cortar madera y le dijo a la niña "espéreme que yo ya casi bajo para que nos vamos juntos", entonces cuando la niña se quedó sola pasó un señor y la iba a coger a la fuerza, eso fue por allá donde es muy solo, en La Curva (Mujer, barrio La Avanzada, 2014).

Allá en La Curva hace tres meses apuñalearon a una muchacha por robarle la moto, ella no era de aquí y vino a visitar a un muchacho y él la mató ahí en La Curva, y como eso es solo y oscuro (Mujer, barrio La Avanzada, 2014).

Esos dos lugares generan en las mujeres sentimientos de temor, miedo y padecimiento porque allí han ocurrido casos de violencias de género, lo que impide la apropiación por parte de ellas. Las mujeres describen La Curva y El Plan como lugares con escaso alumbrado público, solitarios y rodeados de árboles, condiciones que no generan seguridad:

Allá en La Curva hay alumbrado público pero es muy poco, lo otro es que ahí solo hay una institución educativa y no hay casas alrededor, a la gente le da mucho miedo porque es muy solo y el camino es como una Y. Yo me siento insegura cuando paso por la $\mathrm{Y}$, eso queda por donde las hermanas, no paso por allá de noche porque es muy solo. Otro lugar es El Plan, por donde uno voltea cuando sube por el CAI, que uno se encuentra una pinera, ahí también es muy oscuro y muy solo (Mujer, barrio La Avanzada, 2014).

A continuación se localizan los lugares del miedo para las mujeres del barrio La Avanzada: 

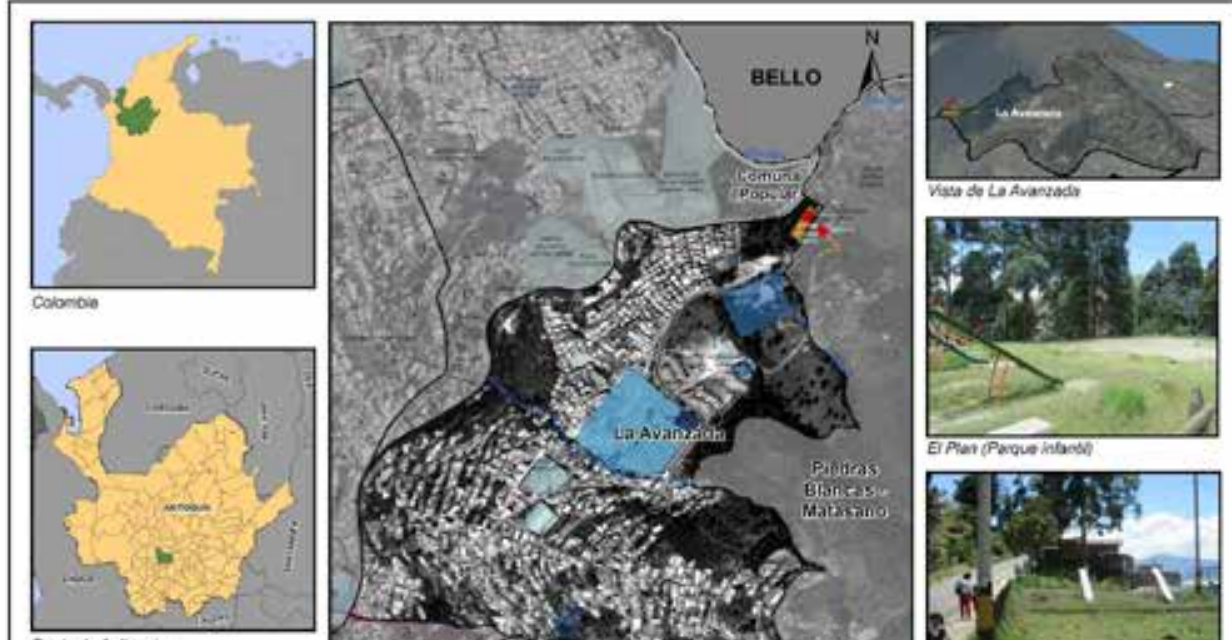

NARRATIVAS FEMENINAS SOBRE EL TERRITORIO

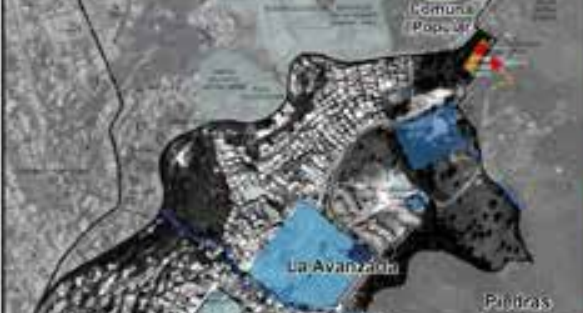

Kata de La Avantady

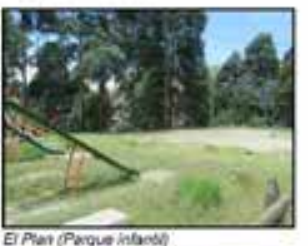

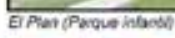
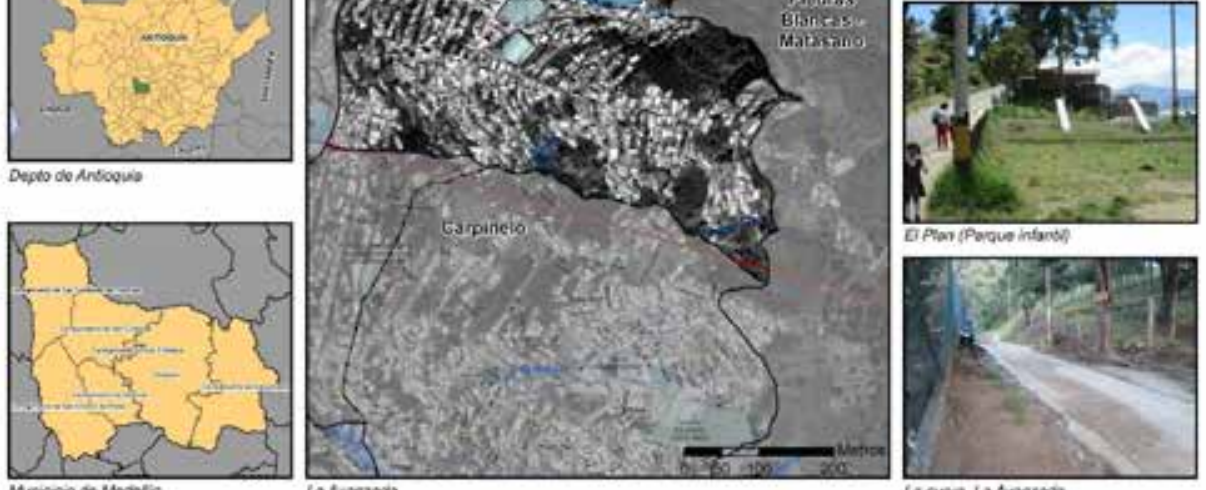

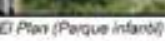
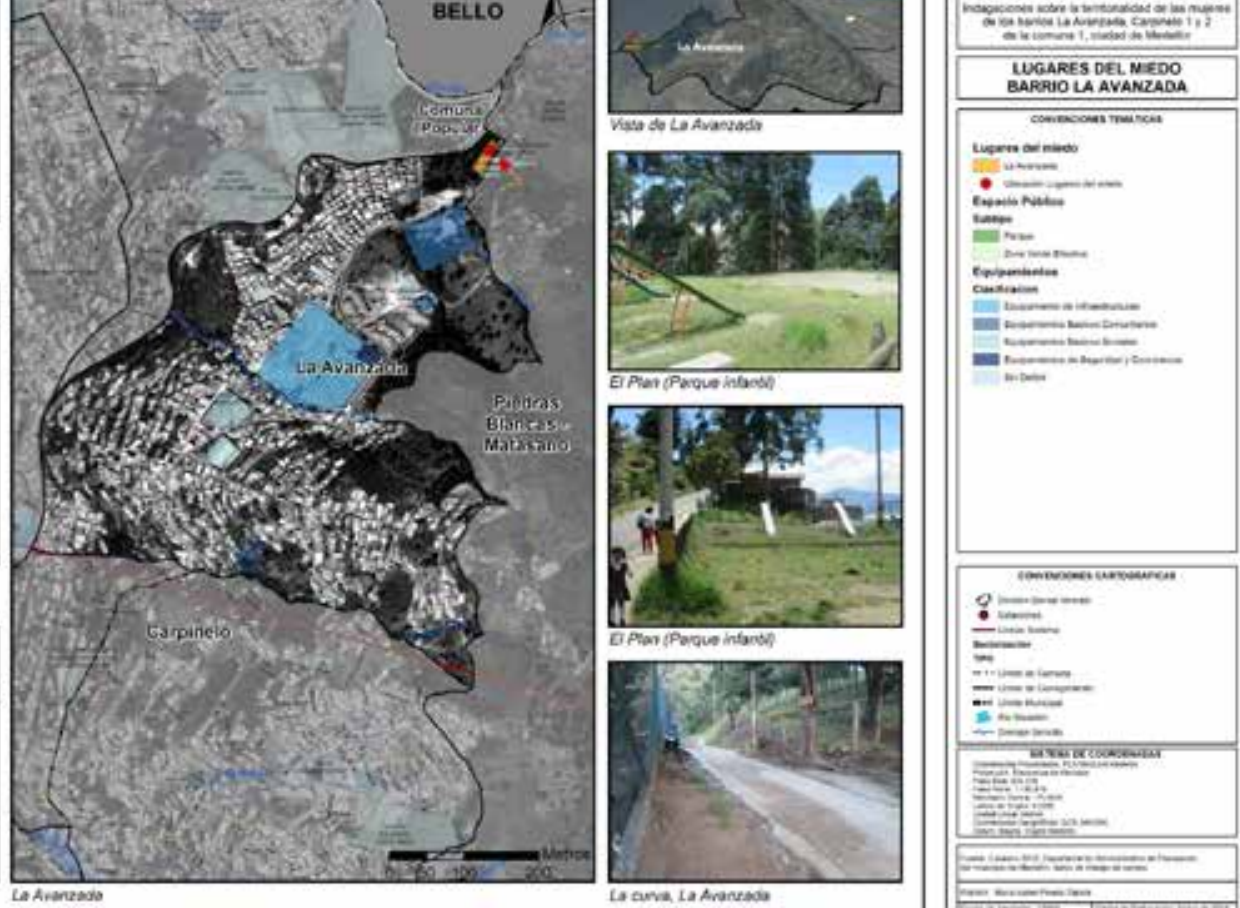

WGARES DEL $N$ SDO

ARPIO LA AVANZADA

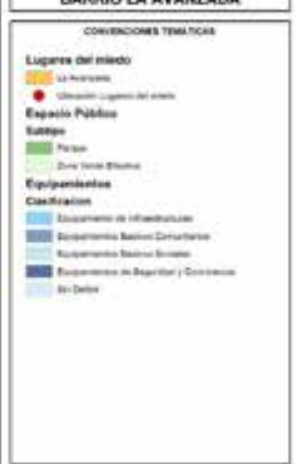

thenes

La Araneado

Lama La Anareacoso

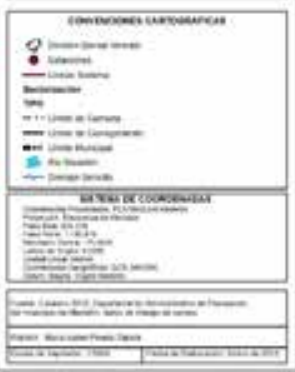

FIGURA 1.

Lugares del miedo, barrio La

Avanzada.

Fuente: elaboración propia.

Por su parte, las mujeres del barrio Carpinelo identificaron, desde sus narrativas, el Parque de la Cruz y la Cancha El Compromiso como lugares del miedo. El primero es un escenario natural que limita con el Parque Arví ${ }^{4}$ (corregimiento de Santa Elena); es descrito por algunas mujeres como:
4 Parque Arví es una propuesta ecoturística localizada en corregimiento de Santa Elena, creada para el disfrute de toda la comunidad local, nacional e internacional. Es un espacio de equidad y participación ciudadana. Es un parque abierto desarrollado en predios de uso público que, mediante la construcción de una oferta turística organizada, permite consolidar una estrategia de conservación y promoción de las potencialidades y fortalezas del corregimiento.
Al cerro, el Parque de la Cruz, sube el más guapo $^{5}$, porque si uno deja ir a las niñas por allá no llegan o llegan medias. Qué pesar, ese parque es muy lindo, pero qué pasa, que allá van solamente los viciosos, mariguaneros. Es un parque muy grande, muy lleno de árboles, cuando los niños quieren ir uno saca tiempo para ir con ellos para cuidarlos y mirar que no les pase nada (Mujer, barrio Carpinelo, 2014).

Para las mujeres, el Parque de la Cruz es un lugar apropiado por algunas familias, principalmente los días domingo, para la realización de actividades

5 Término popular que refiere valentía. 
recreativas y de esparcimiento en grupo: compartir alimentos, elevar cometas, observar la ciudad, jugar en el parque infantil y conversar.

Entre el lunes y el sábado, el lugar es apropiado por hombres para el consumo de sustancias psicoactivas y para "vigilar" el territorio. La apropiación que hacen las mujeres de ese lugar no es individual, dado que el sentimiento de seguridad está asociado a la compañía de otros. Por otra parte, para llegar al Parque de la Cruz se deben transitar caminos conformados por escaleras, en la ruta hay poco alumbrado público, las viviendas son más escasas a medida que se sube por la montaña y la maleza se torna turbia e impide la visibilidad en ciertos tramos.

El Parque de la Cruz, aunque es un lugar del miedo, para las mujeres adultas y lideresas es un referente instalado en la memoria, dado que su construcción fue el resultado del trabajo colectivo realizado en la década del noventa, época en la que fue un referente importante para la comunidad; esa dinámica inicial del lugar fue cambiando cuando otros actores se lo apropiaron, transformando el significado de "lugar para el compartir con el otro" al de "espacio peligroso, oscuro, solo" y donde han ocurrido asesinatos y violaciones de mujeres. La ubicación de estos dos lugares se puede observar a continuación:
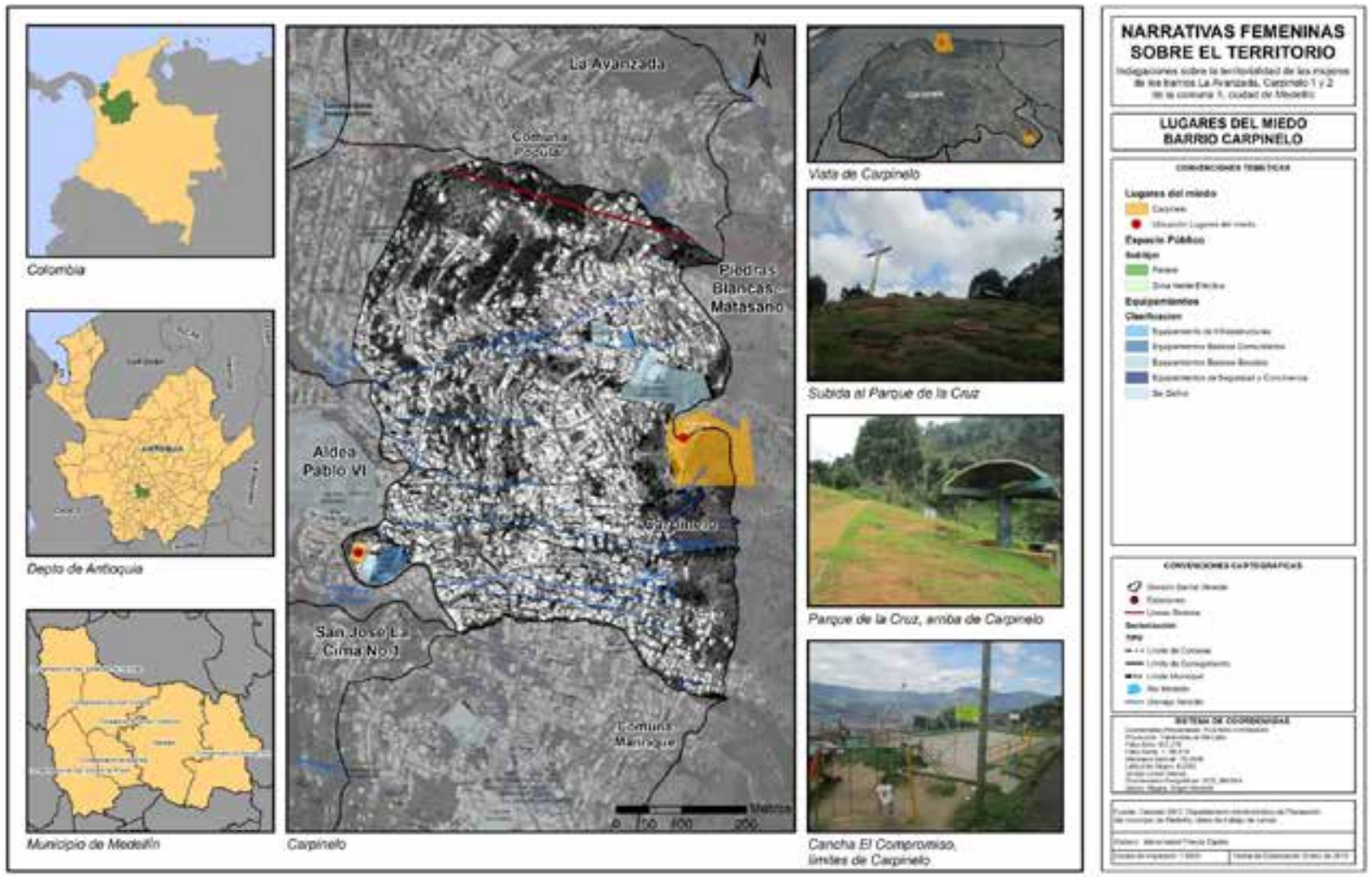

FIGURA 2.

Lugares del miedo, barrio Carpinelo.

Fuente: elaboración propia. 
La Cancha El Compromiso es otro lugar del miedo para las mujeres porque allí hombres jóvenes consumen y expenden sustancias psicoactivas. Las mujeres identifican, además, que el lugar es más inseguro para las jóvenes, lo que les impide su apropiación y limita los espacios para el deporte y el esparcimiento de las niñas y las mujeres. Este lugar es un escenario deportivo conformado por una cancha de microfútbol y un parque infantil y, aunque tiene condiciones adecuadas de iluminación y no es un lugar solitario, sí es un límite de Carpinelo con el barrio El Compromiso, lo que ha generado tensiones y enfrentamientos entre los grupos al margen de la ley o "combos" que se han disputado históricamente el control del territorio, el negocio del microtráfico y las extorsiones en los dos barrios.

Tal y como lo argumenta Abilio Vergara (2013), los lugares tienen dialectos propios: el nombramiento de los lugares del miedo en La Avanzada (E1 Plan y La Curva) está asociado a las formas y las características topográficas del territorio, mientras que los lugares del miedo del barrio Carpinelo (Parque de la Cruz y Cancha El Compromiso) están asociados, el primero, a un simbolismo religioso que ha estado presente en la historia del barrio, y el segundo, a un equipamiento deportivo ubicado en el límite con el barrio El Compromiso.

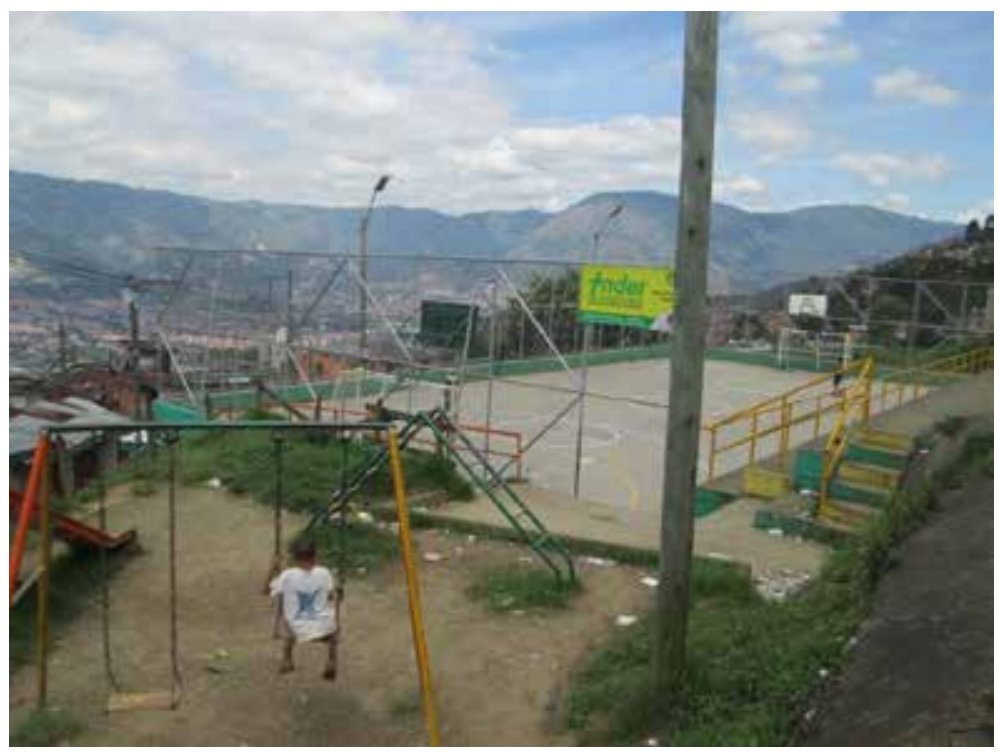

FIGURA 3.

Cancha El Compromiso, barrio Carpinelo, Comuna 1.

Fuente: elaboración propia.

\subsection{Lugares de la memoria}

Para las mujeres de La Avanzada, la Piedra del Gallinazo es un lugar de la memoria asociado a las violencias, cuyas manifestaciones tejen percepciones pasadas y presentes: lugar de castigo, lugar de riesgo para la vida y la seguridad de las mujeres y lugar donde "se botan los cuerpos sin vida". Estas percepciones limitan la apropiación de este lugar:
El sector del chispero, en la Piedra del Gallinazo, también es peligroso porque los muchachos que mandan acá usan ese espacio para castigar a la gente, eso es más arriba de la cancha, eso no es una casa, sino que eso es monte que hay arriba de la cancha (Mujer, barrio La Avanzada, 2014).

La no apropiación y uso de ese lugar es producido por el miedo, sentimiento que se instala en la memoria 
individual y colectiva porque allí ocurrieron hechos significativos asociados al asesinato y la tortura de personas conocidas y desconocidas:

En la época de la violencia allá torturaban y mataban a la gente, pero por allá casi nunca transita la gente, ese lugar es en una manga, ya terminando el barrio, y ya ese lugar tienen un estereotipo, es yendo para Santa Elena, la gente conoce eso allá como la Piedra del Gallinazo, a eso le dicen así porque como allá tiraban a los muertos o los enterraban siempre habían gallinazos parados en esa piedra, allá llevaban a los muertos de Santo Domingo, de toda parte, es decir, ese era el botadero (Mujer, barrio La Avanzada, 2014).

La ubicación del lugar de la memoria nombrado como "la Piedra del Gallinazo" puede verse a continuación:
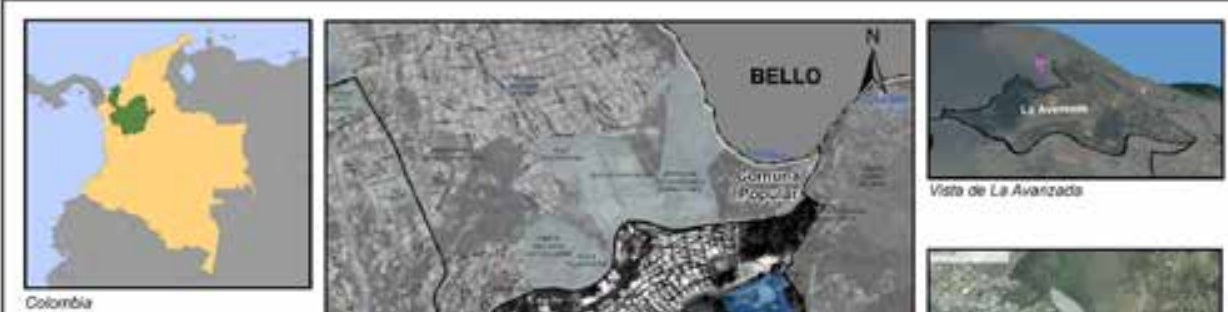

NARRATIVAS FEMENINAS

SOBRE EL. TERRITORIO

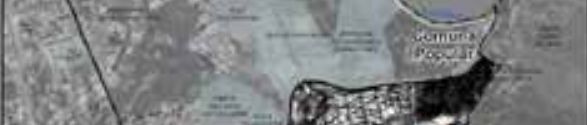

Visto do Lavasiac
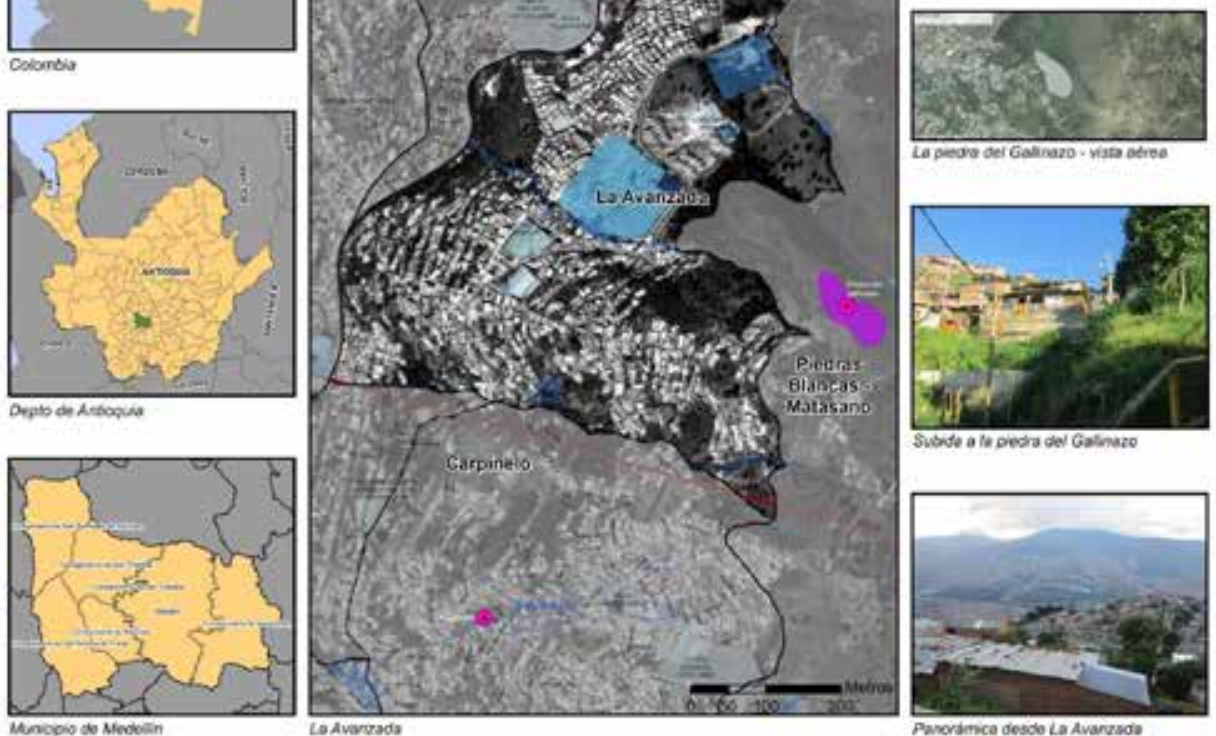

Subrte a le pedra del Golniaso

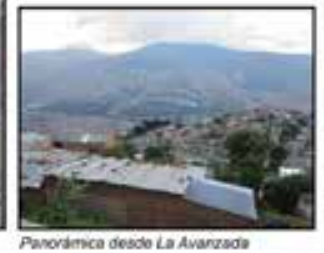

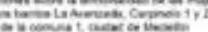

WUGARES DE LA MEVORLA BARHIO LA AVANZNOA

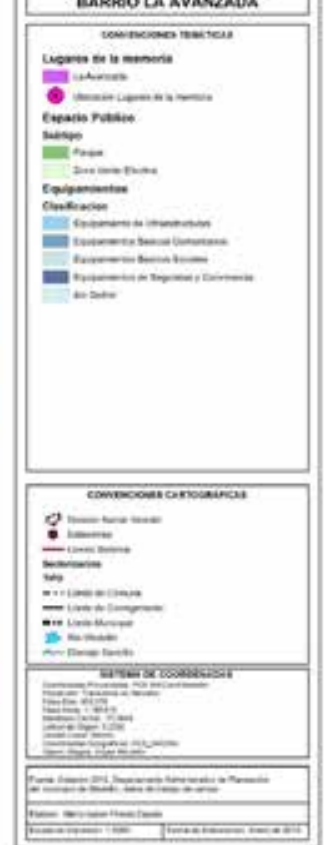

FIGURA 4

Lugares de la memoria, barrio La Avanzada.

Fuente: elaboración propia. 
Para las mujeres de Carpinelo, un lugar de la memoria es el que se conoce como "La Cañada", que es descrito como:

El matadero público, allá tiraban a todos los muertos, esa es la cañada que nos separa de Granizal, es la quebrada El Zancudo. Hace unos meses tiraron a un muerto, pero era más frecuente en el 2004 y 2005. En la cañada es muy oscuro, casi siempre que uno pasa está dañada la lámpara (Mujer, barrio Carpinelo, 2014).

En la Piedra del Gallinazo y La Cañada se mezclan y condensan el miedo y la memoria, allí las experiencias cotidianas, individuales y colectivas que las mujeres han vivenciado posibilitan el surgimiento y la trasferencia, desde la oralidad, de imaginarios sociales que toman forma y se personifican en mitos:

Allá dicen que espantan y que la gente oye voces, yo una vez oí voces (Mujer, barrio La Avanzada, 2014).

Se destaca que en la narración de los lugares del miedo aparezca el personaje masculino de poncho y sombrero, y es significativo que para las mujeres el personaje que acompaña el lugar del miedo sea hombre; ello podría comprenderse, entre otros motivos, por el estereotipo cultural que le asigna a lo masculino características de fuerza, violencia y agresión hacia las mujeres.

Estos lugares se instalaron en la memoria desde el miedo. Según testimonios de algunas mujeres del barrio La Avanzada, en la Piedra del Gallinazo reposan víctimas de la violencia urbana, y aunque la comunidad debe sanar los dolores producidos por la guerra y la muerte, lamentablemente "esos terrenos ahora los están vendiendo y uno ve que están construyendo casas" (Mujer del barrio La Avanzada, 2014).
Por su parte, las mujeres del barrio Carpinelo recuerdan el lugar conocido como La Cañada de esta forma:

Yo, cuando estaba pequeña, esa cañada era llena de cruces, llegó un momento en donde ya no cabían y no volvieron a poner eso, cuando uno pasaba eso por allá era lleno de altares (Mujer, barrio Carpinelo, 2014).

Las manifestaciones socioculturales de adornar, hacer altares y señalizar con cruces son formas para conservar en la memoria de la comunidad el lugar donde cayeron los muertos, para que pervivan en el recuerdo las víctimas y el costo de la violencia en el barrio.

La Piedra del Gallinazo es un lugar por donde las mujeres evitan transitar y del cual difícilmente se apropian en su vida cotidiana porque la poca iluminación y las extensas áreas verdes favorecen la ocurrencia de casos e intentos de violencia y abuso sexual hacia ellas:

Hace poquito a una de las niñas del barrio la iban a violar allá en la Piedra del Gallinazo (Mujer, barrio La Avanzada, 2014).

Contrario a ello, La Cañada es un paso obligado para las mujeres que tienen la necesidad de caminar desde Carpinelo hasta la estación Santo Domingo del Metrocable como una estrategia para ahorrar costos de transporte.

La Cañada es un paso obligado para ir a Santo Domingo, para allá abajo y para el Metrocable y ahorrarse un pasaje (Mujer, barrio Carpinelo, 2014).

Los relatos que las mujeres de los barrios La Avanzada y Carpinelo van tejiendo condensan las cons- 
trucciones sociales e individuales del miedo producido por la violencia urbana, por los asesinatos y las violaciones, miedo que está presente en la cotidianidad y que se instaura en las narrativas y las representaciones sociales que hacen las mujeres de los lugares. En los relatos construidos por las mujeres aparecen imágenes y personajes que encarnan las amenazas sentidas; miedo y memoria se conjugan para instaurar en el imaginario explicaciones y sentidos ante eventos de la cotidianidad.
Por su parte, la manera de nombrar los lugares de la memoria, como en el caso de la Piedra del Gallinazo, sintetiza simbólicamente las situaciones de violencia, con el gallinazo como animal relacionado con la presencia de cuerpos en descomposición, mientras que La Cañada, como lugar de la memoria del barrio Carpinelo, no es únicamente la nominación del hecho natural, sino que singulariza la relación con el territorio como evocación. El mapa que se presenta a continuación muestra la ubicación del lugar de la memoria para las mujeres de Capinelo:
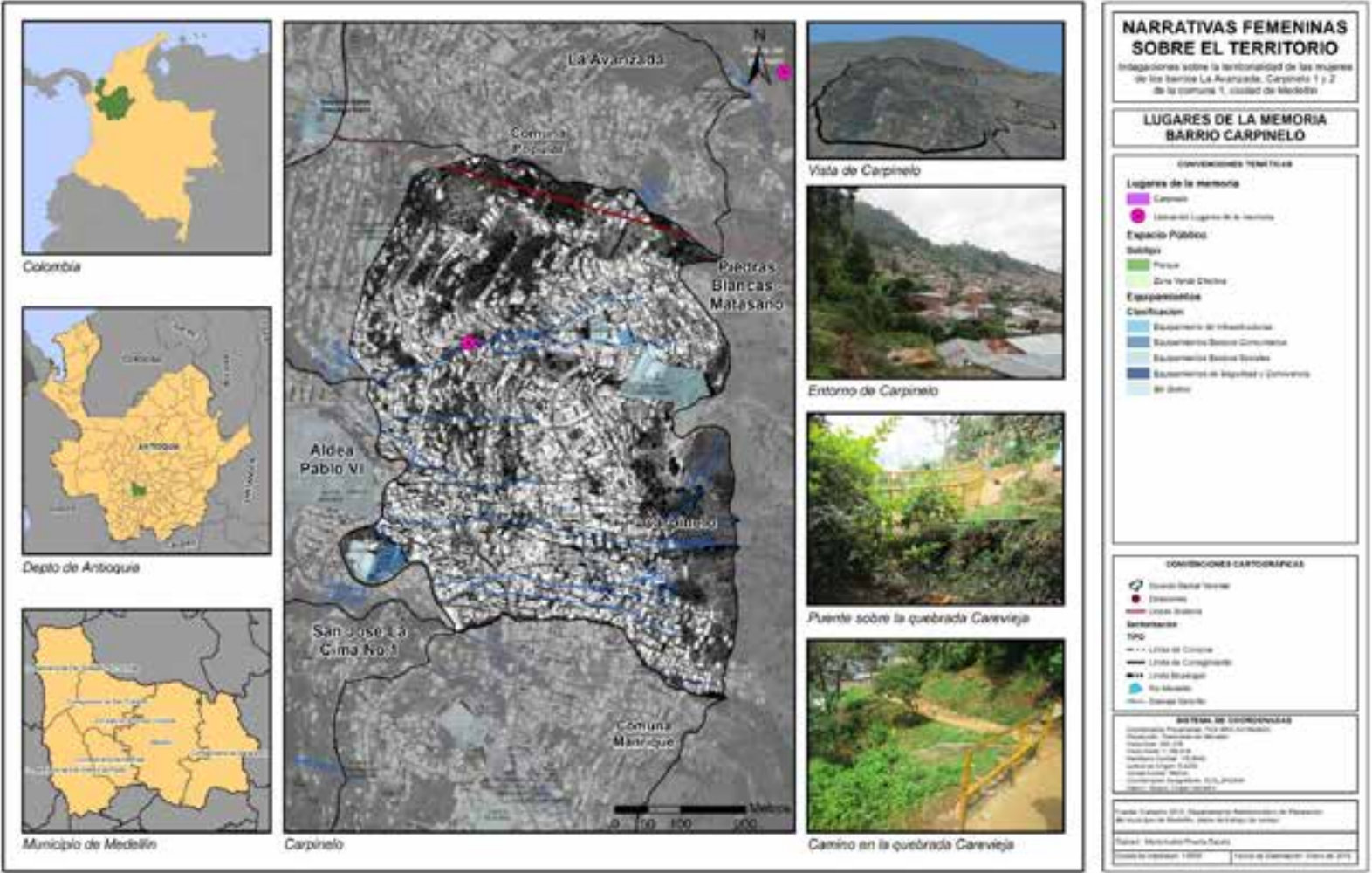

\section{FIGURA 4.}

Lugar de la memoria, barrio Carpinelo.

Fuente: elaboración propia. 
Los lugares nombrados hacen parte de la memoria de las mujeres de La Avanzada y Carpinelo porque allí ocurrieron y vivenciaron experiencias que marcaron sus vidas desde la violencia. Las mujeres narran el sentido que le dan a estos lugares no solo como una reconstrucción de un pasado cargado de diferentes manifestaciones de violencia urbana, sino también como una experiencia que está presente en sus vidas cotidianas y que les impide apropiarse de estos lugares de manera libre y segura. En estos lugares las mujeres experimentan distintas emociones: temor, vulnerabilidad e inseguridad, porque el recuerdo individual y colectivo que emerge es el asociado a la muerte violenta y al abandono de cuerpos sin vida.

\section{Territorios seguros para las mujeres}

El sentido de la territorialidad como significación para las mujeres de los barrios La Avanzada y Carpinelo está mediado por las vivencias subjetivas y sociales, pasadas y presentes que determinan sus percepciones y sus apropiaciones de algunos lugares: las violencias basadas en género, las restricción de la movilidad, el control del territorio y del microtráfico, los asesinatos selectivos, "tirar" los cuerpos sin vida y el uso controlado que hacen los hombres de estos lugares son algunas de las manifestaciones de violencia que se instalan en la memoria de las mujeres y perviven como imágenes y sentimientos que se condensan en lugares específicos del territorio.

La geografía feminista propone el concepto agorafobia como el temor que experimentan las mujeres en lugares públicos y se puede afirmar que las mujeres experimentan este sentimiento en los lugares del miedo y la memoria, dado que son percibidos como peligrosos. Esta construcción social e individual que hacen las mujeres de la agorafobia es reforzada por prácticas sociales y del ejercicio del control territorial que hacen los hombres en ciertos lugares, como, por ejemplo, el uso exclusivo de parques y zonas verdes para consumir y vender sustancias psicoactivas y el control de áreas estratégicas para vigilar el territorio. Por último, es importante señalar que la agorafobia, el temor y la vulnerabilidad que sienten las mujeres de La Avanzada y Carpinelo en los lugares del miedo y la memoria son producto, entre otras cosas, de manifestaciones de violencias basadas en género, donde las mujeres son víctimas de abusos, intimidaciones, acoso, violaciones y asesinatos.

Otro concepto propuesto desde la geografía feminista es el confinamiento, referido a la legitimación de ciertos usos y la restricción de la movilidad más allá de fronteras físicas. En ese sentido, la investigación evidenció que algunos lugares de los barrios, como canchas y parques, son usados exclusivamente por hombres, ya sea para la práctica de deportes socialmente considerados masculinos como el futbol o para consumir y expender sustancias psicoactivas. El uso que hacen las mujeres de estos lugares es controlado tanto por otros miembros de las familias para "vigilar" y dar seguridad a las niñas y mujeres jóvenes como por programas institucionales que propician el uso de las mujeres en horas y días determinados.

Aunque las mujeres de La Avanzada y Carpinelo manifestaron que en el territorio no hay fronteras indivisibles, ellas están confinadas en el territorio porque no se les permite el uso de ciertos lugares que son controlados por actores al margen de la ley o no son apropiados por el temor a ser agredidas. El temor que las mujeres de los barrios La Avanzada y Carpinelo sienten en algunos lugares denota, de un lado, la subjetividad en la construcción del miedo y, de otro, la socialización de las mujeres en una 
cultura que refuerza el estereotipo de su debilidad, indefensión y vulnerabilidad. Tal y como se evidenció con el trabajo de campo, la apropiación y el uso que hacen las mujeres del territorio reproduce la idea según la cual se hace necesario controlar o acompañar a las mujeres en ciertos lugares que son percibidos como peligrosos, lo cual limita la vivencia del territorio desde la autonomía y la seguridad.

La existencia de lugares del miedo produce que las mujeres, en algunas ocasiones, tengan que modificar sus recorridos y su movilidad cotidiana para evitarlos, igual que en el caso de los lugares de la memoria que se instalan en la vida y los imaginarios de las mujeres desde referentes violentos, donde el miedo impide que las mujeres se apropien, usen y recorran libremente el territorio. La inseguridad que sienten las mujeres en algunos lugares desestimula su uso, su apropiación y sus recorridos, sensación de inseguridad causada por condiciones físicas, actividades ilícitas que se realizan, control por parte de actores de ciertos lugares, horarios en los cuales se concentra el desarrollo de ciertas actividades y lejanía con respecto a viviendas $\mathrm{u}$ otros equipamientos.

Este sentimiento de vulnerabilidad que experimentan las mujeres en los lugares del miedo y la memoria influye en cómo las mujeres se relacionan con el espacio público, escenario tradicionalmente reservado para los hombres, así como en el espacio privado y doméstico, culturalmente asignado a las mujeres, en donde también tienen que afrontar la violencia intrafamiliar.

Finalmente, la apuesta es incluir la voz de las mujeres en el diseño del territorio, lo cual implica superar la visión tradicional del urbanismo y la planificación territorial como dispositivo de saber-poder, es decir, como una actividad profesional que posee una espe- cificidad desde la racionalidad científico-técnica de la organización física del espacio que solo es ejercida por aquellos que detentan el conocimiento a nivel profesional y como un ejercicio que legitima unas metáforas asociadas al deber ser de la organización espacial. Lo anterior implica que la academia se pregunte por la visión del sujeto universal y cognitivo que se ha privilegiado en la planeación de la ciudad y que desconoce o no reconoce las miradas de niñas, jóvenes y mujeres en la construcción de territorios.

\section{Conclusiones}

En los territorios es posible identificar lugares del miedo y de la memoria para las mujeres en los que se condensan experiencias subjetivas y sociales, además de sentimientos, en muchos casos, asociados a situaciones de violencias de género que restringen o limitan su goce. Con las mujeres participantes de la investigación fue posible evidenciar que la apropiación y el uso que establecen en sus territorios están directamente permeados por las condiciones de vulnerabilidad y temor que sienten en ciertos lugares, percibidos como inseguros y poco protectores de sus vidas.

Para las mujeres, la oscuridad, los espacios vacíos y las extensas zonas verdes son elementos que incrementan su vulnerabilidad en el territorio. Por el temor a ser víctimas de algún tipo de violencia basada en género, las mujeres limitan el uso y la apropiación de los lugares del miedo y la memoria. Es por ello que la identificación de estos lugares para las mujeres y con las mujeres permitirá la generación de estrategias de intervención territorial para que las ciudades sean más seguras y además posibilitará que sean reconocidas como protagonistas en el desarrollo y la planificación del territorio desde un enfoque de género. 


\section{Referencias}

Buckingham, S. (2010). Análisis del derecho a la ciudad desde una perspectiva de género. En A. Sugranyes y C. Mathivet (eds.), Ciudades para tod@s. Por el derecho a la ciudad, propuestas y experiencias. Santiago de Chile: Coalición Internacional para el Hábitat.

Corporación Convivamos. (2009). Plan de Desarrollo Comuna 1. Medellín, Colombia: Alcaldía de Medellín.

Departamento Administrativo de Planeación. (2011). Perfil Socioeconómico Comuna 1. Popular. Medellín: Alcaldía de Medellín.

Departamento Administrativo de Planeación. (2012). Encuesta de Calidad de Vida 2012. Medellín, Colombia: Alcaldía de Medellín.

Durán, M. A. (1998). La ciudad compartida. Conocimiento, afecto y uso. Madrid: Consejo Superior de los Colegios de Arquitectos de España.

Escobar, A. (2005). Más allá del Tercer Mundo. Globalización y diferencia. Bogotá: Instituto Colombiano de Antropología e Historia.

Javeau, C. (2000). Lugares de la memoria individuales y estructuración de las interacciones: acerca de los síndromes de Lamartine y de Proust. En: L. Alicia (coord.), La vida cotidiana y su espacio temporalidad (pp.171-186). Ciudad de México: Anthropos.

Lagarde, M. (1996). Género y feminismo. Desarrollo humano y democracia. Madrid: Horas y Horas.

Massolo, A. (2005). Género y seguridad ciudadana: el papel y el reto de los gobiernos locales. ECA, Estudios Centroamericanos, 681-682, 643-658.

McDowell, L. (1999). Género, identidad y lugar. Madrid: Ediciones Cátedra, Universidad de Valencia e Instituto de la Mujer.

Niño Murcia, S. (2002). Eco del miedo en Santafé de Bogotá e imaginarios de sus ciudadanos. En: J. Delumeau, M. T. Uribe de Hincapié y J. Giraldo (eds.), EI miedo: reflexiones sobre su dimensión social y cultural (pp. 189-212). Medellín: Corporación Región.

Observatorio de Seguridad Humana de Medellín. (2012). Control territorial y resistencias, una lectura desde la seguridad humana. Medellín: Universidad de Antioquia.

Personería de Medellín. (2013). Informe sobre la situación de los Derechos Humanos en la ciudad de Medellín, 2012. Medellín, Colombia: Alcaldía de Medellín.

Sánchez, L. A., Jaramillo, A. M. y Villa, M. I. (2004). Miedo y desplazamiento, experiencias y percepciones. Medellín: Corporación Región.

Secretaría de las Mujeres de la Alcaldía de Medellín. (2011). Medellín, ciudad segura para las mujeres y mujeres seguras para la ciudad. Estrategia de seguridad pública para las mujeres. Medellín: Alcaldía de Medellín.

Vergara, A. (2013). Etnografía de los lugares. Ciudad de México: Ediciones Navarra. 